\title{
A Study to Compare the Safety and Efficacy of Solifenacin, Tamsulosin and Tadalafil in Relieving Double-J Stent Related Symptoms
}

\author{
Appiya Ramamoorthy Balaji, Pritam Pritish Patnaik, Javangula Venkata Surya Prakash, \\ Sattanathan Vetrichandar, Krishnan Vembu Arasi, Arun Kumar Paranjothi, \\ Vetrivel Natarajan
}

Department of Urology \& Renal Transplantation, Government Stanley Medical College \& Hospital, Chennai, India

Email: pritam1900@gmail.com

How to cite this paper: Balaji, A.R., Patnaik, P.P., Prakash, J.V.S., Vetrichandar, S., Arasi, K.V., Paranjothi, A.K. and Natarajan, V. (2020) A Study to Compare the Safety and Efficacy of Solifenacin, Tamsulosin and Tadalafil in Relieving Double-J Stent Related Symptoms. Open Journal of Urology, 10, 42-51.

https://doi.org/10.4236/oju.2020.103006

Received: December 9, 2019

Accepted: January 28, 2020

Published: January 31, 2020

Copyright $\odot 2020$ by author(s) and Scientific Research Publishing Inc. This work is licensed under the Creative Commons Attribution International License (CC BY 4.0).

http://creativecommons.org/licenses/by/4.0/

\begin{abstract}
Objective: To evaluate and compare the safety and efficacy of Solifenacin, Tamsulosin, and Tadalafil in treating ureteral stent related symptoms (SRS) in patients with indwelling Double-J ureteral stents. Materials and Methods: A prospective randomized controlled study was conducted on 146 consecutive patients in the department of urology, Government Stanley Medical College \& Hospital, Chennai, Tamilnadu, India between Sept 2017-March 2019, with SRS after taking informed consent and confirming DJ Stent position by X-ray KUB post-operatively. Patients were randomized into 4 groups: Group A (Placebo), Group B (Solifenacin $5 \mathrm{mg}$ ), and Group B (Tamsulosin $0.4 \mathrm{mg}$ ) and group D (Tadalafil $5 \mathrm{mg}$ ) at end of 1st week till the removal of DJ stent at end of 3 weeks. All patients were assessed for bothersome lower urinary tract symptoms (LUTS) using the validated Ureteral Stent Symptom Questionnaire (USSQ) at 1st week and 3 weeks after the starting of medications. Appropriate statistical analysis as carried out and the level of significance was set at $\mathrm{P}<$ 0.05. Results: LUTS, general health, and work performance improved with Solifenacin, Tamsulosin and Tadalafil and all the three were comparable in relieving urinary symptoms. Tadalafil was better at relieving body pain, additional problems and sexual problems better than Tamsulosin. Tadalafil showed comparable improvement in LUTS, better sexual health and decreased body pain compared to solifenacin, whereas the latter had better general health, additional problems \& work performance scores. Conclusion: Solifenacin is more effective than Tamsulosin in alleviating LUTS associated with SRS and both show a distinctive advantage over placebo. PDE inhibitor Tadalafil can also be tried for SRS and is as effective as antimuscarinics and $\alpha$-blockers in relieving urinary symptoms and is more efficacious in relieving sexual symptoms and body pain.
\end{abstract}




\section{Keywords}

Double J Stent, Lower Urinary Tract Symptoms (LUTS), Stent Related Symptoms (SRS), Solifenacin, Tadalafil, Tamsulosin, Ureteral Stent Symptom Questionnaire (USSQ)

\section{Introduction}

Ureteral stents, which are widely used for urinary tract disease were introduced by Zimskind et al. in 1967 [1]. The double-J stent, which is the most common form of ureteral stent, is used in urolithiasis, obstructive pyelonephritis, for relief of ureteral obstruction, ureteral edema, and as a ureteral splint in various open, laparoscopic, and endourological procedures and also for iatrogenic ureteric injuries [2] [3].

However, DJ stent often leads to morbid lower urinary tract symptoms (LUTS) such as frequency (50\% - 60\%), urgency (57\% - 60\%), dysuria (40\%), flank pain (19\% - 32\%), suprapubic pain (30\%), and hematuria (25\%), affecting QoL in around $80 \%$ of patients [4] [5]. Around 32\% report sexual dysfunction, and $58 \%$ report reduced work capacity Etiology of SRS may be attributed to the pressure transmission to the renal pelvis during urination and trigonal irritation by the intravesicular part of the stent [6].

USSQ developed by Joshi et al. is a validated self-administered questionnaire for evaluating stent related symptoms. Out of various strategies to minimize SRS, pharmacotherapy is the simplest and noninvasive option. Drugs like alpha-blockers, anticholinergics, phosphodiesterase inhibitors (PDE5Is) and analgesics have been tried for relieving symptoms [7]. Anticholinergics improve SRS by reducing the involuntary bladder contraction occurring due to trigone irritation. Solifenacin, an antimuscarinic agent antagonizes the M3 muscarinic receptors (responsible for the parasympathetic detrusor contraction), thereby decreasing the smooth muscle tone in the bladder and bladder neck relaxation leading to voiding pressure and urinary reflux reduction, thereby alleviating the irritative LUTS of SRS and decrease in pain noticed during voiding. Tamsulosin, a selective $\alpha$-1a/1d blocker, inhibits contraction of the smooth muscles in distal ureter, bladder trigone, and neck, relieving LUTS and flank pain. PDE-5 receptors are present over lower ureter, trigone, and bladder neck and Tadalafil, a PDE-5 inhibitor, increases the levels of cGMP leading to relaxation of the smooth muscle of the ureter, helps relieve sexual dysfunction, bladder outlet obstruction related LUTS and lower ureteric stone expulsion [8]. Several previous studies have shown the effectiveness of the pharmacotherapeutic agents used in this study in relieving SRS. For eg., Rohit et al. had concluded the combination of Solifenacin and Silodosin (a blocker) to be effective in controlling SRS [9]. A study by Whang $\mathrm{J}$ et al. also advocated solifenacin and tamsulosin to be safe and equally efficacious for reducing SRS with no added advantage of combination 
therapy over the monotherapy [10].

The purpose of this study was, therefore, to analyze and assess the effectiveness of antimuscarinic (solifenacin), a selective alpha-1-blocker (tamsulosin) and PDE inhibitor (Tadalafil) in improving SRS of patients with indwelling double-J ureteral stents as compared to placebo.

\section{Materials and Methods}

A prospective, randomized placebo-controlled study was conducted on $146 \mathrm{pa}$ tients (98 male, 48 female) after obtaining informed consent in our department of urology from September 2017 to March 2019. After obtaining a proper history, physical examination was done in all the patients. Investigations like urinalysis with urine culture, renal function tests (RFT), ultrasonography (USG), X-ray of the kidneys, ureters, and bladder (KUB) and computed tomography (CECT) KUB were performed for all patients before surgery.

All patients 18 - 60 years undergoing unilateral routine DJ stenting after an endourological surgery [either unilateral percutaneous nephrolithotomy (PCNL) or ureteroscopic lithotripsy (URSL)] were enrolled in the study for evaluation.

Exclusion criteria-(Age $<18$ and $>60$ years), pregnant women, Patients with residual stone after procedure, B/L DJ stenting, long term Stents, solitary kidney or congenital urinary abnormality, any patient with a previous history of prostate disease (BPH, prostatitis or carcinoma prostate) or overactive bladder on medications. Patients having a previous or present history of prostatic or bladder surgery, lower urinary tract surgery, malignancy, medical treatment ( $\alpha$ blockers, beta-blockers, calcium antagonists, PDE5 inhibitors, anticholinergics and cholinergics, nitrates).

PCNL was done using 24 Frnephroscope and stone clearance was done with EMS Lithoclast master. The decision for stent placement was taken by the operating urologist, depending upon large stone burden, mucosal trauma, and need for ureteral dilation to access tight ureters. URSL was done with an 8.0/9.5 Frureteroscope (Wolf) and pneumatic lithotripter. $5 \mathrm{Fr}$ and $26 \mathrm{~cm}$ long DJ stent composed of polyurethane material was inserted under fluoroscopy guidance.

Postoperatively stent position was confirmed by X-ray KUB. On the day of surgery, injection of ceftriaxone 1 gmiv was given prophylactically to all patients. Foleys catheter was removed on 1st post-op day in both URSL and PCNL patients. On 2nd post-op day, nephrostomy tube was removed in PCNL patients. A short course of ciprofloxacin $500 \mathrm{mg}$ (twice daily) was given postoperatively, as per our institutional protocol. Patients were informed about possible SRS and USSQ forms were given at discharge. USSQ is a self-administered questionnaire that addresses various domains of health (6 sections and 38 items) affected by indwelling DJ stents covering urinary symptoms (scorem 1 - 11), pain (1 - 9), general health $(1-6)$, work performance $(1-7)$, sexual health $(1-4)$ and additional problems $(1-4)$. They were asked to come after 1 week with the completed questionnaire if they experienced symptoms. Scoring at 1st week was 
done to see the magnitude and severity of SRS.

After applying inclusion and exclusion criteria, 153 patients reported DJ-related symptoms at 1st week out of which, 7 patients were not willing to participate in the study so a total of 146 patients were equally randomized into 4 groups (A, B, $\mathrm{C}$, and $\mathrm{D}$ ). Double blinding was done to minimize bias. The allotment was done by the staff nurse and neither the patient nor the researcher was aware of drugs allocation to the above groups. Group A received placebo, group B was given tab Solifenacin $5 \mathrm{mg}$ once daily, group $\mathrm{C}$ was advised tab Tamsulosin $0.4 \mathrm{mg}$ once a night after food \& group D was instructed to take tab Tadalafil $5 \mathrm{mg}$ once daily after meals. The side effects of the drugs were explained to patients and were asked to come after 14 days of therapy (at 3rd week) with provided USSQ (Figure 1 shows the study design).

Collected data were tabulated in an excel sheet and analyzed using IBM SPSS Modeler 18.1 (201, 7 Armonk, NY: IBM Corp.) for descriptive and inferential statistics under the supervision of a statistician. Data were calculated by the Student $t$-test, and ANOVA test was used for the association of the variables within the four groups, and the level of significance was set at $\mathrm{P}<0.05$.

\section{Results}

The majority of the patients presented to this hospital were of low socioeconomic class, occupation ranging from daily laborers to farmers, shopkeepers and domestic helps as well as students, government employees and nonworking women from southern states of India (Tamilnadu, Andhrapradesh, Kerala \& Karnataka).

Out of 200 eligible patients, 153 developed SRS. Since 7 patients did not consent for the study, a total of 146 patients were enrolled in this study. The final study sample was reduced to 121 due to patients lost to follow-up (11) and patients requiring urgent stent removal due to hematuria (8) or severe uti (4) and due to stent migration (2). However, drug-related side effects did not warrant exclusion in any of the groups.

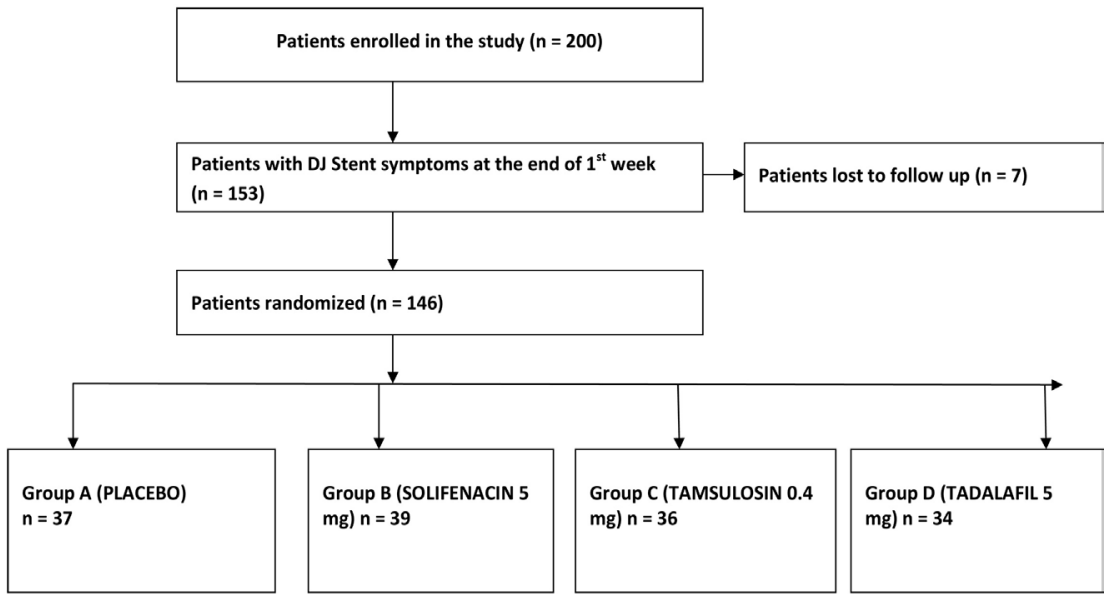

Figure 1. The study design. 
Out of 200 patients, 153 patients complained of DJ related symptoms (76.5\%). Mean age, male to female ratio, average height, and procedures performed were uniform in all 3 groups. Table 1 shows the patient's characteristics.

Table 2 and Table 3 show the USSQ of all groups at 1st and 3rd week respectively and Table 4 shows the difference between 1st and 3rd weeks. USSQ was similar in all groups at 1st week but decreased significantly in groups B, C, and

Table 1. Table showing patient's characteristics.

\begin{tabular}{ccccc}
\hline Features & $\begin{array}{c}\text { Group A } \\
\text { Placebo }\end{array}$ & $\begin{array}{c}\text { Group B } \\
\text { Solifenacin }\end{array}$ & $\begin{array}{c}\text { Group C } \\
\text { Tamsulosin }\end{array}$ & $\begin{array}{c}\text { Group D } \\
\text { Tadalafil }\end{array}$ \\
\hline No of Patients & 29 & 32 & 31 & 29 \\
Age & 35.8 & 37.0 & 34.1 & 32 \\
M:F & $20: 9$ & $21: 11$ & $23: 8$ & $25: 4$ \\
BMI (in kg/m $\left.{ }^{2}\right)$ & 19.8 & 20.5 & 19.9 & 19 \\
PCNL & 9 & 8 & 7 & 7 \\
URSL & 20 & 24 & 24 & 22 \\
\hline
\end{tabular}

Table 2. USSQ components at the end of the 1st week.

\begin{tabular}{|c|c|c|c|c|c|}
\hline \multirow{2}{*}{ Features } & Group & A & $\mathrm{B}$ & $\mathrm{C}$ & $\mathrm{D}$ \\
\hline & No & 29 & 32 & 31 & 29 \\
\hline \multirow[t]{4}{*}{ Urinary Symptoms } & Minimum & 25 & 11 & 11 & 12 \\
\hline & maximum & 56 & 50 & 51 & 48 \\
\hline & Mean & 46.7 & 42 & 43.3 & 43 \\
\hline & SD & 5.3 & 6.1 & 6.3 & 5.5 \\
\hline \multirow[t]{4}{*}{ Body Pain } & Minimum & 11 & 3 & 3 & 4 \\
\hline & Maximum & 21 & 22 & 24 & 26 \\
\hline & Mean & 18 & 16 & 16.5 & 21 \\
\hline & SD & 2.7 & 2.9 & 2.8 & 2.4 \\
\hline \multirow[t]{4}{*}{ Sexual Health } & Minimum & 6 & 3 & 2 & 2 \\
\hline & Maximum & 12 & 9 & 10 & 11 \\
\hline & Mean & 10 & 8 & 7 & 9 \\
\hline & SD & 1.6 & 1.8 & 1.7 & 1.7 \\
\hline \multirow[t]{4}{*}{ General Health } & Minimum & 11 & 12 & 14 & 12 \\
\hline & Maximum & 27 & 28 & 28 & 26 \\
\hline & Mean & 25.6 & 20 & 22 & 22 \\
\hline & SD & 4.1 & 3.3 & 3.1 & 3.4 \\
\hline \multirow[t]{4}{*}{ Work Performance } & Minimum & 12 & 6 & 4 & 4 \\
\hline & Maximum & 15 & 17 & 15 & 16 \\
\hline & Mean & 15 & 12 & 12 & 15 \\
\hline & $\mathrm{SD}$ & 2.3 & 2.1 & 2.1 & 2.4 \\
\hline \multirow[t]{4}{*}{ Additional Problems } & Minimum & 7 & 12 & 4 & 8 \\
\hline & Maximum & 18 & 19 & 20 & 16 \\
\hline & Mean & 16.6 & 12 & 11 & 12 \\
\hline & $\mathrm{SD}$ & 2.1 & 2.1 & 1.9 & 2.3 \\
\hline
\end{tabular}


Table 3. USSQ components at the end of 3rd week.

\begin{tabular}{|c|c|c|c|c|c|}
\hline \multirow{2}{*}{$\begin{array}{l}\text { Features (At the end of } \\
\qquad 3 \text { weeks) }\end{array}$} & Group & A & B & C & $\mathrm{D}$ \\
\hline & No & 29 & 32 & 31 & 29 \\
\hline \multirow[t]{4}{*}{ Urinary Symptoms } & Minimum & 16 & 4 & 5 & 5 \\
\hline & maximum & 50 & 27 & 26 & 28 \\
\hline & Mean & 43 & 21 & 22.9 & 23.5 \\
\hline & SD & 4.8 & 4.7 & 4.2 & 4.4 \\
\hline \multirow[t]{4}{*}{ Body Pain } & Minimum & 11 & 4 & 3 & 3 \\
\hline & Maximum & 20 & 18 & 12 & 14 \\
\hline & Mean & 17.8 & 12 & 14 & 08 \\
\hline & $\mathrm{SD}$ & 4.8 & 0.9 & 2.1 & 5.2 \\
\hline \multirow[t]{4}{*}{ Sexual Health } & Minimum & 4 & 2 & 5 & 1 \\
\hline & Maximum & 9 & 7 & 11 & 6 \\
\hline & Mean & 8.6 & 5 & 6.5 & 2 \\
\hline & $\mathrm{SD}$ & 1.7 & 2.3 & 2.5 & 1.7 \\
\hline \multirow[t]{4}{*}{ General Health } & Minimum & 13 & 8 & 7 & 8 \\
\hline & Maximum & 25 & 20 & 21 & 21 \\
\hline & Mean & 24.9 & 12 & 17 & 18 \\
\hline & $\mathrm{SD}$ & 2.6 & 4.4 & 3.7 & 3.8 \\
\hline \multirow[t]{4}{*}{ Work Performance } & Minimum & 11 & 5 & 4 & 4 \\
\hline & Maximum & 16 & 16 & 12 & 14 \\
\hline & Mean & 14 & 10 & 10 & 12 \\
\hline & $\mathrm{SD}$ & 2.1 & 2.4 & 2.2 & 2.3 \\
\hline \multirow[t]{4}{*}{ Additional Problems } & Minimum & 8 & 4 & 5 & 3 \\
\hline & Maximum & 18 & 16 & 14 & 14 \\
\hline & Mean & 16.2 & 9 & 8 & 11 \\
\hline & SD & 2.5 & 2.9 & 2.7 & 2.3 \\
\hline
\end{tabular}

Table 4. The difference (of symptom score) between 1st and 3rd weeks.

\begin{tabular}{ccccccccccc}
\hline \multirow{2}{*}{ Characteristics } & \multicolumn{2}{c}{ Group A } & \multicolumn{2}{c}{ Group B } & \multicolumn{2}{c}{ Group C } & \multicolumn{2}{c}{ Group D } & P value \\
\cline { 2 - 10 } & Mean & SD & Mean & SD & Mean & SD & Mean & SD & \\
\hline Urinary Symptoms & 3.7 & 5.0 & 21 & 4.7 & 20.4 & 7.0 & 19.5 & 5.9 & $<0.0001$ \\
Body Pain & 0.2 & 7.1 & 4 & 4.4 & 2.5 & 4.7 & 13 & 6.3 & $<0.0001$ \\
Sexual Health & 1.4 & 4.8 & 3 & 3.5 & 0.5 & 3.9 & 7 & 5.2 & $<0.0001$ \\
General Health & 0.7 & 6.3 & 8 & 5.1 & 5 & 4.6 & 4 & 5.8 & $<0.0001$ \\
Work Performance & 1 & 5.7 & 2 & 3.2 & 2 & 1.8 & 7 & 4.9 & $<0.0001$ \\
& & & & & & & & & \\
Additional Problems & 0.4 & 4.2 & 3 & 5.1 & 3 & 3.8 & 1 & 4.4 & $<0.0001$ \\
\hline
\end{tabular}


$\mathrm{D}$ at the end of 3 weeks. Placebo does not lead to an improvement in symptom scores over the study period. Solifenacin group showed the best improvement in urinary symptoms [mean score 42 (at end of 1st week)-21 (at 3rd week); almost $50 \%$ reduction, better than that seen in the other three groups]. Improvement in Sexual health $[>80 \%$ reduction of the mean score ( 9 to 2 over a period of two weeks)] and reduction of body pain (mean difference $=9$; SD-6.3) was more with Tadalafil as compared to others. USSQ scores of additional problems were the least in Tamsulosingroup (SD of symptom reduction-3.8; $\mathrm{P}<0.0001$ ) and general health improvement was more with Solifenacin (mean difference of scores at end of 1 st and 3 rd weeks $=8$ ). Also, analgesic requirement was significantly less in the Tadalafil group as compared to both Tamsulosin and the placebo group.

\section{Discussion}

Indwelling double J (DJ) stents are an integral part of endourological procedures for relief or prevention of ureteral obstruction [1]. However many patients develop stent-related symptoms (SRS) which may lead to morbidity and reduced QoL [11]. Trigonal irritation causes mainly irritative LUTS like frequency, urgency, and nocturia or pressure transmitting to the renal pelvis during urination causing flank pain. Stent friction in the pelvicalyceal system or ureter or the bladder due to physical activity or reduced urine output can cause hematuria [12]. Joshi et al. reported an $80 \%$ reduction in patient's quality of life (QoL) due to SRS after DJ-stenting [5]. The USSQ consists of six domains-urinary symptoms, body pain, general health, work performance, sexual performance, and other/additional problems. The urinary symptoms domain has 11 questions. The body pain domain consists of the pain experience, visual analog scale, and six questions. Work performance has seven questions. General health and sexual performance domains have six and four questions respectively. Each question has 4 to 7 scores. Scores from each question are added to give a total score, and a higher score indicates more bothersome symptoms. Various strategies (preventive and pharmaceutical) have been applied for better compatibility of stents. Preventive strategies include minimum use of stents, stent length adjusted according to patients' height, proper positioning, changes in stent design like biodegradable stents, hydrophilic material coating tapered distal end of these stents, stent coating, drug-eluting stents and proper patient counseling regarding symptoms [13] [14] [15].

It had been suggested that drugs like alpha-blockers and anticholinergics decrease the pressure transmitted toward the renal pelvis during micturition, reduce the peak contraction pressure leading to ureteral dilation and decrease the bladder irritation due to intravesical portion of the stent [16]. Wang et al. suggested that the selective alpha-1-blocker tamsulosin improved urinary symptoms, flank pain, and pain during voiding [17]. Alpha-blockers are commonly used drugs for SRS and various other researchers have also found that these 
drugs are effective in reducing SRSs [7] [17] [18] [19].

PDE-5 inhibitors are FDA approved drugs for erectile dysfunction, LUTS due to prostatic hyperplasia, and pulmonary hypertension. PDE5i receptors are present at lower ureter, bladder neck, and trigone. Antagonism of these receptors reduces ureteral spasm, relaxes the ureteric smooth muscle, and promotes expulsion of calculi and improvement of irritative urinary symptoms and recent studies have also shown the role of PDE5Is in SRS [8].

This study compared the safety and effectiveness of antimuscarinic (Solifenacin), alpha-blocker (Tamsulosin) \& PDE inhibitor (Tadalafil) for relieving SRS and found all the drugs to be beneficial in reducing the score in all the domains of the USSQ as compared to placebo, thereby suggesting a statistically significant advantage over placebo with very minimal side effects (dry mouth, dizziness, headache \& fatigue) and good compliance. The results of this study are in similar lines \& supported by data from various previous studies done by several authors (described below) with the pharmaco-therapeutical agent(s) used in this study design.

Aggarwal et al. had also compared tadalafil, tamsulosin, and placebo in patients with SRS and found tadalafil to be more effective than tamsulosin in relieving body pain, improving general and sexual health states with similar improvements in rest of the domain of USSQ in both groups (tamsulosin and tadalafil) as compared to placebo [20].

J wang et al., Rohit B et al. have also shown the effectiveness of solifenacin and or tamsulosin in their papers [9] [10]. Vinod $\mathrm{K}$ et al. also found tadalafil to be more effective then Tamsulosin in relieving body pain, sexual symptoms and improving general health and work performance but less effective in improvement of urinary symptoms [21].

\section{Conclusion}

SRS has a major impact on the patient's daily life. Solifenacin, Tamsulosin, and Tadalafil are effective drugs for relieving these symptoms with improved QOL and less requirement of analgesic compared to placebo. Tadalafil is as effective as Tamsulosin in relieving urinary symptoms but more effective in relieving sexual symptoms and body pain. Therefore Tadalafil could be recommended as a preferred drug in sexually active patients undergoing DJ stenting for relieving SRS.

\section{Limitations}

Being a single-center study and use of single stent design and material with a small sample size in each group and the study sample representing a specific demographic variable (even though the data was adequately calculated), studies with multicentre designs can be more helpful to validate our results.

\section{Conflicts of Interest}

The authors declare no conflicts of interest regarding the publication of this paper. 


\section{References}

[1] Zimskind, P.D., Fetter, T.R. and Wilkerson, J.L. (1967) Clinical Use of Long-Term Indwelling Silicone Rubber Ureteral Splints Inserted Cystoscopically. Journal of Urology, 97, 840-844. https://doi.org/10.1016/S0022-5347(17)63130-6

[2] Chew, B.H., Knudsen, B.E. and Denstedt, J.D. (2004) The Use of Stents in Contemporary Urology. Current Opinion in Urology, 14, 111-115.

https://doi.org/10.1097/00042307-200403000-00011

[3] Jeong, H., Kwak, C. and Lee, S.E. (2004) Ureteric Stenting after Ureteroscopy for Ureteric Stones: A Prospective Randomized Study Assessing Symptoms and Complications. BJU International, 93, 1032-1034. https://doi.org/10.1111/j.1464-410X.2004.4776a.X

[4] Joshi, H.B., Okeke, A., Newns, N., Keeley, F.X. and Timoney, A.G. (2002) Characterization of Urinary Symptoms in Patients with Ureteral Stents. Urology, 59, 511-516. https://doi.org/10.1016/S0090-4295(01)01644-2

[5] Joshi, H.B., Stainthorpe, A., MacDonagh, R.P., Keeley, F.X. and Timoney, A.G. (2003) Indwelling Ureteral Stents: Evaluation of Symptoms, Quality of Life and Utility. Journal of Urology, 169, 1065-1069. https://doi.org/10.1097/01.ju.0000048980.33855.90

[6] Thomas, R. (1993) Indwelling Ureteral Stents: Impact of Material and Shape on Patient Comfort. Journal of Endourology, 7, 137-140. https://doi.org/10.1089/end.1993.7.137

[7] Tsai, P.C., Wang, C.J., Chang, C.H., Chen, H.W. and Hsu, C.S. (2015) Effects of Silodosin on Lower Urinary Tract Symptoms Due to a Double-J Stent: A Prospective Randomized Study. International Journal of Nephrology and Kidney Failure, 1, 1-4. https://doi.org/10.16966/2380-5498.118

[8] Hajebrahimi, S., Farshi, A., Jabbari, A., Bazargani, H.S., Babaei, H. and Mostafaie, H. (2015) Does Tadalafil Alleviate Ureteral Stent Related Symptoms? A Randomized Controlled Trial. European Urology Supplements, 14, e1080. https://doi.org/10.1016/S1569-9056(15)61068-5

[9] Rohit, B., Vinay, T., Yadav, S.S. and Devendra, S.D. (2018) Comparison of Safety and Efficacy of Silodosin, Solifenacin, Tadalafil and Their Combinations in the Treatment of Double-J Stent-Related Lower Urinary System Symptoms: A Prospective Randomized Trial. Turkish Journal of Urology, 44, 228-238. https://doi.org/10.5152/tud.2018.50328

[10] Wang, J., Zhang, X., Zhang, T., Mu, J., Bai, B. and Lei, Y. (2017) The Role of Solifenacin, as Monotherapy or Combination with Tamsulosin in Ureteral Stent-Related Symptoms: A Systematic Review and Meta-Analysis. World Journal of Urology, 35, 1669-1680. https://doi.org/10.1007/s00345-017-2051-3

[11] Dyer, R.B., Chen, M.Y., Zagoria, R.J., Regan, J.D., Hood, C.G. and Kavanagh, P.V. (2002) Complications of Ureteral Stent Placement. RadioGraphics, 22, 1005-1022. https://doi.org/10.1148/radiographics.22.5.g02se081005

[12] El-Faqih, S.R., Shamsuddin, A.B., Chakrabarti, A., Atassi, R., Kardar, A.H. and Osman, M.K. (1991) Polyurethane Internal Ureteral Stents in the Treatment of Stone Patients: Morbidity Related to Indwelling Times. Journal of Urology, 146, 1487-1491. https://doi.org/10.1016/S0022-5347(17)38146-6

[13] Beiko, D.T., Knudsen, B.E. and Denstedt, J.D. (2004) A Double-Blind Randomized Controlled Trial Assessing the Safety and Efficacy of Intravesical Agents for Ureteral Stent Symptoms after Extracorporeal Shockwave Lithotripsy. Journal of Endou- 
rology, 17, 195-199. https://doi.org/10.1089/089277903765444294

[14] Rane, A., Saleemi, A., Cahill, D., Sriprasad, S., Shrotri, N. and Tiptaft, R. (2001) Have Stent-Related Symptoms Anything to Do with Placement Technique? Journal of Endourology, 15, 741-745. https://doi.org/10.1089/08927790152596352

[15] Multanen, M., Tammela, T.L., Laurila, M., Seppälä, J., Välimaa, T., Törmälä, P., et al. (2002) Biocompatibility, Encrustation and Biodegradation of Ofloxacin and Silver Nitrate Coated Poly-L-Lactic Acid Stents in Rabbit Urethra. Urological Research, 30, 227-232. https://doi.org/10.1007/s00240-002-0252-7

[16] Avila, M.M., Arteaga, L.G. and Guzman, R.J. (2016) Efficacy of Tamsulosin, Oxybutynin, and Their Combination in the Control of Double-J Stent-Related Lower Urinary Tract Symptoms. IBJU, 42, 487-493. https://doi.org/10.1590/S1677-5538.IBJU.2015.0186

[17] Wang, C.J., Huang, S.W. and Chang, C.H. (2009) Effects of Specific Alpha-1A/1D Blocker on Lower Urinary Tract Symptoms Due to Double-J Stent: A Prospectively Randomized Study. Urological Research, 37, 147-152. https://doi.org/10.1007/s00240-009-0182-8

[18] Kwon, J.K., Cho, K.S., Oh, C.K., Kang, D.H., Lee, H., Ham, W.S., et al. (2015) The Beneficial Effect of Alpha-Blockers for Ureteral Stent-Related Discomfort: A Systematic Review and Network Meta-Analysis for Alfuzosin versus Tamsulosin versus Placebo. BMC Urology, 15, 55. https://doi.org/10.1186/s12894-015-0050-5

[19] He, F., Man, L. and Li, G. (2016) Efficacy of $\alpha$-Blocker in Improving Ureteral Stent-Related Symptoms: A Meta-Analysis of Both Direct and Indirect Comparison. Drug Design, Development and Therapy, 10, 1783-1793. https://doi.org/10.2147/DDDT.S103195

[20] Aggarwal, S.P., Priyadarshi, S., Tomar, V., Yadav, S.S., Gangkak, G., Vyas, N., et al. (2015) A Randomized Controlled Trial to Compare the Safety and Efficacy of Tadalafil and Tamsulosin in Relieving Double J Stent Related Symptoms. Advances in Urology, 2015, Article ID: 592175. https://doi.org/10.1155/2015/592175

[21] Chauhan, V.K., Singla, M.K., Dumra, A., et al. (2019) Efficacy and Safety of Tadalafil in Ureteric Stent Related Symptoms: A Double-Blind, Prospective, Randomized Study. International Journal of Research in Medical Sciences, 7, 1472-1478. https://doi.org/10.18203/2320-6012.ijrms20191523 